\title{
Malignant Pleural Mesothelioma : Current Perspectives in Early Detection and Diagnosis
}

\author{
Attapon Cheepsattayakorn ${ }^{1,2 *}$, Ruangrong Cheepsattayakorn ${ }^{3}$, Supawan Manosoontorn ${ }^{4}$ and Vijaya \\ Bhakskara Reddy Mutha ${ }^{5}$ \\ ${ }^{1} 10^{\text {th }}$ Zonal Tuberculosis and Chest Disease Center, Thailand \\ ${ }^{3}$ Department of Pathology, Faculty of Medicine, Chiang Mai University, Thailand \\ 2,4,5Faculty of Public Health, St. Theresa International College, Thailand
}

*Corresponding author: Attapon Cheepsattayakorn, $10^{\text {th }}$ Zonal Tuberculosis and Chest Disease Center, 143 Sridornchai Road, Changklan, Muang, Chiang Mai 50100 Thailand.

Received Date: December 11, 2019

Published Date: January 10, 2020

\section{Abstract}

The objectives of this study are to review epidemiology, novel methods of detection, and novel diagnostics of malignant pleural mesothelioma (MPM) in the literature that were published between 1977 and 2019. Malignant pleural mesothelioma associated with prolonged respirable-asbestosfiber exposure is a rare cancer with constantly increasing incidence and poor prognosis due to lacking the effective treatment options. The median survival ranges from 8 to 14 months. Sarcomatoid histological subtype has the worst prognosis. Video-assisted thoracoscopy plus mediastinoscopy is the current gold standard for staging malignant pleural mesothelioma and is superior to computerized tomography of the chest for assessing the tumor size and suspected nodal metastases. Several circulating biomarkers are detected in MPM patients, such as mesothelin, osteopontin, fibulin-3, high mobility group B1, vascular endothelial growth factor, reactive oxygen species, reactive nitrogen species, micro-ribonucleic acids, tumor deoxyribonucleic acid, etc. In conclusion, there is potential for the development of biomarkers and radiological imaging in the years to come. Its incidence is expected to decrease in the next decade.

Keywords: Pleural; Mesothelioma; Malignant; Diagnosis; Epidemiology

Abbreviations : BALF : Bronchoalveolar lavage; BAP1 : BRCA-associated protein 1; CFAP45 : Cilia and flagella associated protein 45; CT : Computed tomography; CTCs : Circulating tumor cells; ctDNA : circulating tumor Deoxyribonucleic acid; DNA : Deoxyribonucleic acid; FDG : 18-fluoro-deoxyglucose; HMGB1 : High Mobility Group B1 ; miRNAs : micro-Ribonucleic acids; MPM : Malignant pleural mesothelioma; MRI : Magnetic resonance imaging; MSLN : Mesothelin; PDGF : Platelet-derived growth factor; PET-CT : Positron-emission technology-computed tomography; RNS : Reactive nitrogen species; ROS : Reactive oxygen species; RR2 : Ryanodine receptor 2; SETDB1 : Set domain bifurcated 1; SETD2 : Set domain containing 2; SMRP : Soluble mesothelin-related peptide; TGF- $\beta$ : Tumor growth factor- $\beta$; TNM : Tumor-nodes-metastases; UICC : the Union for International Cancer Control ; UK : United Kingdom; ULK2 : Unc-like autophagy activating kinase; USA : United States of America; US FDA : United States Food and Drug Administration; VATS : Video-assisted thoracoscopic surgery; VEGF : Vascular endothelial growth factor

\section{Objectives of the Study}

The objectives of this study are to review epidemiology, novel methods of detection, and novel diagnostics of malignant pleural mesothelioma (MPM) in the literature that were published between 1977 and 2019.

\section{Introduction}

Malignant pleural mesothelioma, a tumor originated from the submesothelial or mesothelial cells of pleura, pericardium, or peritoneum accounts for more than $80 \%$ arising from the pleura that the majority are male patients $[1,2]$. MPM, a rare cancer with increasing incidence and poor prognosis because of lacking the effective therapeutic interventions [1,3-4]. MPM is associated with previous long-term asbestos exposure of about 40 years of latency period [5-9]. The total incidence is highest in the UK and USA whereas the global incidence has increased constantly over the past decade and is predicted to reach the estimated peak in 2020 $[5,6]$. The median survival of MPM ranges from 8 to 14 months from the diagnosis [5-7,10]. Male is predominant of $4: 1$ [10]. Four main histological subtypes of MPM are classified as the following : 1) epithelioid ( most favorable prognosis with a median survival of 13.1 months), 2) sarcomatoid (worst outcomes with a median survival of 4 months), 3) biphasic or mixed, and 4) desmoplastic $[5,6,10]$. 


\section{Pathogenesis}

Prolonged exposure to respirable asbestos fibers triggers an increase in inflammatory cytokines and reactive oxygen species (ROS) in the pleural microenvironment, both of which facilitate MPM carcinogenesis [11,12]. Naturally, asbestos occurs in the form of silicate mineral with two different forms : 1) curly serpentine fibers of chrysotile or "white" asbestos and 2) sharp, needle-like fibers of amphibole asbestos. Amphibole asbestos is divided into 2.1) crocidolite (blue) asbestos, 2.2) amosite (brown) asbestos, 2.3) anthophyllite, 2.4) actinolite, and 2.5) tremolite. The risk of MPM development is associate with the type of fibers and heaviness and duration of exposure [5]. Nevertheless, MPM is characterized by a low mutation load [13], with the most frequently mutated genes involved in MPM pathogenesis, " tumor suppressors (BAP1, CDKN2A, LATS2, NF2) [14]. After asbestos fibers are inhaled and migrate to the pleural space causing pleural irritation and a repeated cycle of tissue damage and repair. Asbestos fibers that penetrate mesothelial cells that cause cell mitosis interference, generating DNA mutation, and altering chromosome structure. These mesothelial cells release inflammatory cytokines, such as plateletderived growth factor (PDGF), tumor growth factor- $\beta$ (TGF- $\beta$ ), and vascular endothelial growth factor (VEGF) that facilitate tumor growth [9]. Asbestos fibers also induce the phosphorylation various protein kinases (extracellular signal-regulated kinase 1 and 2 and mitogen-activated protein) that increases the expression of protooncogenes and facilitating abnormal cellular proliferation [15]. In PMP tumor, there is reduced expression of key molecules in the p53 tumor-suppressor gene pathway (p14, p16, and NF2-MERLIN) [15]. There are deletions and loss mutations of BAP1 (BRCAassociated protein 1), CFAP45 (cilia and flagella associated protein 45), DDX3X, DDX51, RR2 (ryanodine receptor 2), SETDB1 (set domain bifurcated 1), SETD2 (set domain containing 2), and ULK2 (unc-like autophagy activating kinase) [16]. Nevertheless, MPM has a low frequency of protein-altering mutations, approximately 25 mutations per tumor [17] and contributing to the limitations of the potential for molecular targeted therapy [18].

\section{Detection and Diagnosis}

Chest radiological imaging should be performed in all MPMsuspected patients for diagnostic and staging information. Characteristically radiological findings may be nodular pleural thickening, pleural plaques, a localized pleural-mass lesion, pleural effusion, irregular fissural thickening, or loss of hemithoracic volume. Nevertheless, further radiologically imaging tools, such as bedside chest ultrasonography, computed tomographic imaging are usually required due to insensitive and nonspecific chest radiographic features in general [19-22]. Positron-emission technology-computed tomography (PET-CT) combines highresolution computed tomographic (CT) scanning injected with a radioactive metabolic tracer (such as 18-fluoro-deoxy-glucose (FDG)) or magnetic resonance imaging (MRI) [23-25]. Nevertheless, PET-CT has low sensitivity for the diagnosis of extrapleural lesions due to its poor spatial resolution [26]. In addition to CT scanning of the chest, surgical information by video-assisted thoracoscopic surgery (VATS) plus mediastinoscopy which is the current gold standard for staging in MPM and is superior to CT for assessing tumor size and suspected nodal metastasis $[27,28]$ is the consensus by using the International Mesothelioma Interest Group staging classification [29] whereas the European Pneumological Society [30] recommends using the tumor-nodes-metastases (TNM) classification of the Union for International Cancer Control (UICC) [31]. VATS reveal the sensitivity and specificity of 95\%-98\% and $100 \%$, respectively and enables the removal of specimens under visual observation, as well as pleurodesis in the same procedure [28]. VATS also enable the assessment of its respectability [32]. By pleural puncture and cytological diagnosis, tumor cells are identified in pleural effusion more than $50 \%$ of patients with MPM, with the likelihood of positive cytology depending on the MPM subtype with the limited cytological diagnosis [33]. Percutaneous needle biopsy without image guidance reveals the sensitivity and specificity of $7 \%-47 \%$ and $100 \%$, respectively [28].

There are several circulating tumor proteins identified in patients with MPM, such as mesothelin (MSLN, a cell-surface glycoprotein expressed by mesothelial cells) [34-36], osteopontin (an integrin-binding protein implicated in cell-matrix interaction and overexpressed in several types of cancers) [37,38], and fibulin-3 (a secreted glycoprotein implicated in cell proliferation and migration correlated with advanced disease, also identified in pleural fluid) $[39,40]$. Soluble mesothelin-related peptide (SMRP), a soluble form of mesothelin is secreted by the tumor cells into the blood circulation [41-43]. SMRP seems to be effective in predicting response to chemotherapy and patient survival although it is not specific for MPM and cannot be considered an early diagnostic biomarker for MPM surveillance program [41, 44- 48]. Several studies revealed that plasma osteopontin is a more reliable and stable biomarker than serum osteopontin and the data involving its diagnostic accuracy are inadequate [49-51]. Combined measurement of circulating SMRP and osteopontin is not more informative than measurement of circulating SMRP alone $[49,50,52,53]$. Several previous studies demonstrated that fibulin-3 was not beneficial for differentiating patients with MPM from patients affected by other diseases [54] and was not effective as mesothelin [55]. Other biomarkers for detecting MPM are inflammatory and angiogenic factors (High Mobility Group B1 (HMGB1) and VEGF), biomarkers of oxidative stress (Reactive Oxygen Species (ROS) and Reactive Nitrogen Species (RNS)), circulating micro-ribonucleic acids (miRNAs), circulating tumor deoxyribonucleic acid (ctDNA), circulating methylated deoxyribonucleic acid (circulating methylated DNA), and circulating tumor cells (CTCs). A previous study indicated that HMGB1 and its receptors were highly expressed in MPM cell lines and tissues [56]. VEGF, a key stimulator of tumor neoangiogenesis, is overexpressed in MPM tissues [57-59]. In comparison to patients with lung cancer or non-malignant pleural diseases, circulating VEGF levels are increased in pleural effusions of patients with MPM [60]. ROS and RNS are key mediators of asbestos toxicity [61]. 
Bronchoalveolar lavage (BALF) of patients with asbestos exposure demonstrated an increase in various biomarkers of inflammation and altered ROS and iron homeostasis (i.e., iron, lactoferrin, ferritin, transferrin, and transferrin receptors) compared to controls [62]. A previous study on the levels of miR-103a-3p and miR-30e-3p in extracellular vesicles demonstrated that the combination of these two biomarkers discriminated patients with MPM from asbestosexposed controls with a sensitivity of $95.5 \%$ and specificity of 80 $\%$ and were confirmed by normalizing the data to RNU48, miR-99a, miR-638, miR-720, and miR-1274a [63]. In consideration, these miRNAs could be biomarkers of asbestos exposure rather than disease. Upregulation of miR-2053 could be a good prognostic biomarker of MPM [64]. Detection of ctDNA variants in patients with MPM could be a potential biomarker for the diagnosis of MPM [65-67]. Detection of changes in ctDNA methylation could be an early diagnostic and prognostic tool of MPM [68]. CTCs counts in the blood circulation is very low at the early stage and increases in advanced stage of cancer [69 ]. " CTC-chip " test that developed by Chikaishi et al demonstrated better performance than CELLSEARCH® test that is approved by the United States Food and Drug Administration (US FDA) [70,71].

\section{Discussion}

Several circulating biomarkers are investigated for screening and detection of MPM, such as mesothelin, osteopontin, fibulin-3, HMGB1, VEGF, ROS, RNS, miRNAs, ctDNA [34-68]. Additionally, “ CTC-chip " test developed by Chikaishi et al revealed better results than " CELLSEARCH ${ }^{\circledR}$ " test that approved by the US FDA. CTCs counts increases in the MPM patients with advanced stage [69]. The mentioned miRNAs are beneficial biomarkers of asbestos exposure rather than advanced stage MPM. Detection of changing ctDNA methylation could be beneficial in early diagnosis and prognosis of MPM [68] , whereas upregulation of miR-2053 could be a good prognostic biomarker of MPM [64]. For detection of asbestos toxicity, both ROS and RNS are the key mediators [61].

\section{Conclusion}

MPM, a complex disease can cause important morbidity and mortality. MPM remains a diagnostic and therapeutic challenge ambulatory and in-hospital care. There is potential for the development of biomarkers and radiological imaging in the years to come. Its incidence has been constant in recent years and expect to decrease in the next decade.

\section{Authors Contributions}

Dr. Attapon Cheepsattayakorn conducted the study framework and wrote the manuscript. Associate Professor Dr. Ruangrong Cheepsattayakorn contributed to scientific content and assistance in manuscript writing. Both authors read and approved the final version of the manuscript. Both Assistant Professor Dr. Supawan Manosoontorn and Dr. Vijaya Bhakskara Reddy Mutha were responsible for the reference citation search.

\section{Acknowledgment}

None.

\section{Conflict of Interest}

No conflict of interest.

\section{References}

1. Delgermaa V, Takahashi K, Park E, Le G, Hara T, Sorahan T (2011) Global mesothelioma deaths reported to the World Health Organization. 89 : 716-724, 724a-c.

2. Woitowitz H, Hillerdal G, Galvarezos A, Berghäuser K, Rödels-perger K, et al. (1993) Risko und Einflussfaktoren des diffusen malignen Mesotheliomas (DMM) Forschungsberichtsrehe FB 698 Bundesanstalt für Arbeitsschutz.

3. Robinson BM. (2012) Malignant pleural mesothelioma : an epidemiological perspective. Ann Cardiothorac Surg 1:491-496.

4. Vogelzang NJ, Rusthven JJ, Symanowski J, Denham C, Kaukel E, et al. (2003) Phase III study of pemetrexed in combination with cisplatin versus cisplatin alone in patients with malignant pleural mesothelioma. J Clin Oncol 21 : 2636-2644.

5. British Thoracic Society Standards of Care Committee (2007). BTS statement on malignant mesothelioma in the UK, 2007. Thorax 62 : Suppl 2, ii1-ii19.

6. Scherpereel A, Astoul P, Baas P, Berghmans T, Clayson H, et al. (2010) Guidelines of the European Respiratory Society and the European Society of Thoracic Surgeons for the management of malignant pleural mesothelioma. Eur Respir J 35 : 479-495.

7. Yates D, Corrin B, Stidolph P, Browne K (1997) Malignant mesothelioma in south east England: clinicopathological experience of 272 cases. Thorax 52 : 507-512.

8. Howel D, Arblaster L, Swinburne L, Schweiger M, Renvoize E, et al. (1997) Routes of asbestos exposure and the development of mesothelioma in an English region. Occup Environ Med 54 :403-409.

9. Sekido Y (2013) Molecular pathogenesis of malignant mesothelioma. Carcinogenesis 34 : 1413-1419.

10. Beckett P, Edwards J, Fennell D, Hubbard R, Woolhouse I, et al. (2015) Demographics, management and survival of patients with malignant pleural mesothelioma in the National Lung Cancer Audit in England and Wales. Lung Cancer. $88: 344-348$.

11. Carbone M, Yang H (2012) Molecular pathways: targeting mechanisms of asbestos and erionite carcinogenesis in mesothelioma. Clin Cancer Res $18:$ 598-604.

12. Bograd AJ, Suzuki K, Vertes E, Colovos C, Morales EA, et al. (2011) Immune response and immunotherapeutic interventions in malignant pleural mesothelioma. Cancer Immunol Immunother 60 : 1509-1527.

13. Chalmers ZR, Connelly CF, Fabrizio D, Gay L, Ali SM, et al. (2017) Analysis of 100,000 human cancer genomes reveals the landscape of tumor mutational burden. Genome Med 9:34.

14. Bott M, Brevet M, Taylor BS, Shimizu S, Ito T, et al. (2011) The nuclear deubiquitinase BAP1 is commonly inactivated by somatic mutations and 3p21.1 losses in malignant pleural mesothelioma. Nat Genet 43 : 668-672.

15. Robinson BW, Lake RA (2005) Advances in malignant mesothelioma. N Eng J Med $353: 1591-1603$.

16. Illei PB, Rusch VW, Zakowski MF, Ladanyi M (2003) Homozygous deletion of CDKN2A and codeletion of the methylthioadenosine phosphorylase gene in the majority of pleural mesotheliomas. Clin Cancer Res $9: 2108-2113$.

17. Guo G, Chmielecki J, Goparaju C, Heguy A, Dolgalev I, et al. (2015) Whole-exome sequencing reveals frequent genetic alterations in BAP1, NF2, CDKN2A, and CUL1 in malignant pleural mesothelioma. Cancer Res $75: 264-269$.

18. Torti D, Trusolino L (2011) Oncogene addiction as a foundational rationale for targeted anti-cancer therapy: promises and perils. EMBO Mol Med 3:623-636.

19. Salonen O, Kivisaari L, Standertskjöld-Nordenstam CG, Somer K, 
Mattson K, et al. (1986) Computed tomography of pleural lesions with special reference to the mediastinal pleura. Acta Radiologica Diagnosis (Sweden) 27 : 527-531.

20. Havelock T, Teoh R, Laws D, Gleeson F (2010) Pleural procedures and thoracic ultrasound: British Thoracic Society pleural disease guidelines 2010. Thorax 65 : Suppl 2 : i61-i76.

21. Qureshi NR, Rahman NM, Gleeson FV (2009) Thoracic ultrasound in the diagnosis of malignant pleural effusion. Thorax $64: 139-143$.

22. Hierholzer J, Luo L, Bittner RC, Stroszczynski C, Schröder RJ, et al. (2000) MRI and CT in the differential diagnosis of pleural disease. Chest J 118 : 604-609.

23. Benard F, Sterman D, Smith RJ, Kaiser LR, Albelda SM, et al. (1998) Metabolic imaging of malignant pleural mesothelioma with fluorodeoxyglucose positron emission tomography. Chest J. 114 : 713-722.

24. Yildirim H, Metintas M, Entok E, Ak G, Ak I, et al. (2009) Clinical value of fluorodeoxyglucose-positron emission tomography/computed tomography in differentiation of malignant mesothelioma from asbestos-related benign pleural disease : an observational pilot study. J Thorac Oncol $4: 1480-1484$.

25. Treglia G, Sadeghi R, Annunziata S, Lococo F, Cafarotti S, et al. (2014) Diagnostic accuracy of 18F-FDG-PET and PET/CT in the differential diagnosis between malignant and benign pleural lesions : a systematic review and meta-analysis. Acad Radiol $21: 11-20$.

26. Steward D, Waller D, Edwards J, Jeyapalan K, Entwisle J (2003) Is there a role for pre-operative contrast-enhanced magnetic resonance imaging for radical surgery in malignant pleural mesothelioma? Eur J Cardiothorac Surg $24:$ 1019-1024.

27. Heelan R, Rusch V, Begg C, Panicek DM, Caravelli JF, et al. (1999) Staging of malignant pleural mesothelioma: comparison of CT and MR imaging. Am J Roentgenol 172 : 1039-1047.

28. Attanous R, Gibbs A (2006) The comparative accuracy of different pleural biopsy techniques in the diagnosis of malignant mesothelioma. Histopathol $53: 340-344$.

29. Rusch VW (1995) A proposed new international TNM staging system for malignant pleural mesothelioma. Chest. 108 :1122-1128.

30. Scherpereel A, Astoul P, Baas P, Berghmans T, Clayson H, et al. (2010) Guidelines of the European Respiratory Society and the European Society of Thoracic Surgeons for the management of malignant pleural mesothelioma. Eur Respir J. 35 : 479-495.

31. Wittekind C, Meyer H (2010) TNM Klassifikation maligner Tumoren. 7. Auflage. Weinlheim : Wiley-VCH.

32. Hasegawa S, Kondo N, Matsumoto S, Takuwa T, Hashimoto M, et al. (2012) Practical approaches to diagnose and treatment to malignant pleural mesothelioma : a proposal for diagnostic total parietal pleurectomy. Int J Clin Oncol. $17: 33-39$.

33. Husain A, Colby T, Ordonez N, Allen TC, Attanoos RL, et al. (2012) Guidelines for pathologic diagnosis of malignant mesothelioma. Arch Pathol Lab Med. 136: 1-21.

34. Pastan I, Hassan R (2014) Discovery of mesothelin and exploiting it as a target for immunotherapy. Cancer Res. $74: 2907-2912$.

35. Chang K, Pai LH, Batra JK, Pastan I, Willingham MC (1992) Characterization of the antigen (CAK1) recognized by monoclonal antibody $\mathrm{K} 1$ present on ovarian cancers and normal mesothelium. Cancer Res. $52: 181-186$.

36. Chang K, Pai LH, Pass H, Pogrebniak HW, Tsao MS, et al. (1993) Monoclonal antibody $\mathrm{K} 1$ reacts with epithelial mesothelioma but not with lung adenocarcinoma. Lung Cancer. $8: 336$.

37. Coppola D, Szabo M, Boulware D, Muraca P, Alsarraj M, et al. (2004) Correlation of osteopontin protein expression and pathological stage across a wide variety of tumor histologies. Clin Cancer Res. 10 :184190.

38. Pass HI, Lott D, Lonardo F, Harbut M, Liu Z, et al. (2005) Asbestos exposure, pleural mesothelioma, and serum osteopontin levels. N Engl J Med. 353 : 1564-1573.

39. Creaney J, Dick IM, Robison BW (2015) Comparison of mesothelin and fibulin-3 in pleural fluid and serum as markers in malignant mesothelioma. Curr Opin Pulm Med 21 :352-356.

40. Pass HI, Levin SM, Harbut MR (2012) Fibulin-3 as a blood and effusion biomarker for pleural mesothelioma. N Engl J Med 367 : 1417-1427.

41. Scholler N, Fu N, Yang Y, Ye Z, Goodman GF, et al. (1999) Soluble member(s) of the mesothelin/megakaryocyte potentiating factor family are detectable in sera from patients with ovarian carcinoma. Proc Natl Acad Sci USA 96 : 11531-11536.

42. Hollevoet K, Reitsma JB, Creaney J, Grigoriu BD, Robinson BW, et al. (2012) Serum mesothelin for diagnosing malignant pleural mesothelioma: an individual patient data meta-analysis. J Clin Oncol $30: 1541-1549$.

43. Rai AJ, Flores RM, Mathew A, Gonzalez-Espinoza R, Bott M, et al. (2010) Soluble mesothelin-related peptides (SMRP) and osteopontin as protein biomarkers for malignant mesothelioma : analytical validation of ELISA-based assays and characterization at mRNA and protein levels. Clin Chem Lab Med $48: 271-278$.

44. Beyer HL, Geschwindt RD, Glover CL, Tran L, Hellstrom I, et al. (2007) A potential test for malignant pleural mesothelioma. Clin Chem 53 : 666-672.

45. Ordonnez NG (2003) Value of mesothelin immunostaining in the diagnosis of mesothelioma. Mod Pathol 16:192-197.

46. Cristaudo A, Foddis R, Vivaldi A, Guglielmi G, Dipalma N, et al. (2007) Clinical significance of serum mesothelin in patients with mesothelioma and lung cancer. Clin Cancer Res 13:5076-5081.

47. Grigoriu BD, Scherpereel A, Devos P, Chahine B, Letourneux M, et al. (2007) Utility of osteopontin and serum mesothelin in malignant pleural mesothelioma diagnosis and prognosis assessment. Clin Cancer Res $13: 2928-2935$.

48. Schneider J, Hoffmann H, Dienemann H, Herth FJ, Meister M, et al. (2008) Diagnostic and prognostic value of soluble mesothelinrelated proteins in patients with malignant pleural mesothelioma in comparison with benign asbestosis and lung cancer. J Thorac Oncol 3 : 1317-1324.

49. Cristaudo A, Bonotti A, Simonini S, Vivaldi A, Guglielmi G, et al. (2011) Combined serum mesothelin and plasma osteopontin measurements in malignant pleural mesothelioma. J Thorac Oncol 6:1587-1593.

50. Creaney J, Yeoman D, Musk AW, de Klerk N, Skates SJ, et al. (2011) Plasma versus serum levels of osteopontin and mesothelin in patients with malignant mesothelioma-which is best? Lung Cancer $74: 55-60$.

51. Foddis R, Bonotti A, Landi S, Fallahi P, Guglielmi G, et al. (2018) Biomarkers in the prevention and follow-up of workers exposed to asbestos. J Thorac Dis 10 : S360-S368.

52. Hollevoet K, Nackaerts K, Gosselin R, de Wever W, Bosquee L, et al. (2011) Soluble mesothelin, megakaryocyte potentiating factor, and osteopontin as markers of patient response and outcome in mesothelioma. J Thorac oncol $6: 1930-1937$.

53. Wheatley-Price P, Yang B, Patsios D, Patel D, Ma C, et al. (2010) Soluble mesothelin-related peptide and osteopontin as markers of response in malignant mesothelioma. J Clin Oncol $28: 3316-3322$.

54. Kirschner MB, Pulford E, Hoda MA, Rozsas A, Griggs K, et al. (2015) Fibulin-3 levels in malignant pleural mesothelioma are associated with prognosis but not diagnosis. Br J Cancer 113: 963-969.

55. Creaney J, Dick IM, Meniawy TM, Leong SL, Leon JS, et al. (2014) Comparison of fibulin-3 and mesothelin as markers in malignant mesothelioma. Thorax 69 : 895-902.

56. Jube S, Rivera ZS, Bianchi ME, Powers A, Wang E, et al. (2012) Cancer cell secretion of the DAMP protein HMGB1 supports progression in malignant mesothelioma. Cancer Res $72: 3290-3301$. 
57. Kumar-Singh S, Weyler J, Martin MJ, Vermeulen PB, van Marck E (1999) Angiogenic cytokines in mesothelioma : a study of VEGF, FGF1 and -2 , and TGF-beta expression. J Pathol 189:72-78.

58. Strizzi L, Catalano A, Vianale G, Orecchia S, Casalini A, et al. (2001) Vascular endothelial growth factor is an autocrine growth factor in human malignant mesothelioma. J Pathol 193 : 468-475.

59. Demirag F, Unsal E, Yilmaz A, Caglar A (2005) Prognostic significance of vascular endothelial growth factor, tumor necrosis, and mitotic activity index in malignant pleural mesothelioma. Chest $128: 3382$ 3387.

60. Hirayama N, Tabata C, Tabata R, Maeda R, Yasumitsu A, et al. (2011) Pleural effusion VEGF levels as a prognostic factor of malignant pleural mesothelioma. Respir Med 105 : 137-142.

61. Shukla A, Gulumian M, Hei TK, Kamp D, Rahman Q, et al. (2003) Multiple roles of oxidants in the pathogenesis of asbestos-induced diseases. Free Radic Biol Med 34 :1117-1129.

62. Ghio AJ, Stonehuerner J, Richards J, Devlin RB (2008) Iron homeostasis in the lung following asbestos exposure. Antioxid Redox Signal 10 : 371-377.

63. Cavalleri T, Angelici L, Favero C, Dioni L, Mensi C, et al. (2017) Plasmatic extracellular vesicle microRNAs in malignant pleural mesothelioma and asbestos-exposed subjects suggest 2-miRNA signature biomarkers of disease. PLoS ONE 12 : e0176680.
64. Matboli M, Shafei AE, Ali MA, Gaber AI, Galal A, et al. (2019) Clinical significance of serum DRAM1 mRNA, ARSA mRNA, has-miR-2053 and lncRNA-RP1-86D1.3 axis expression in malignant pleural mesothelioma. J Cell Biochem 120 :3203-3211.

65. Fan HC, Blumenfeld YJ, Chikara U, Hudgins L, Quake SR, et al. (2010) Analysis of the size distributions of fetal and maternal cell-free DNA by paired-end sequencing. Clin Chem 56:1279-1286.

66. Corcoran RB, Chabner BA (2018) Application of cell-free DNA analysis to cancer treatment. N Engl J Med 379:1754-1765.

67. Leon SA, Shapiro B, Sklaroff DM, Yaros MJ (1977) Free DNA in the serum of cancer patients and the effect of therapy. Cancer Res 37 : 646-650.

68. Kanherkar RR, Bhatia-Dey N, Csoka AB (2014) Epigenics across the human lifespan. Front Cell Dev Biol 2: 49.

69. Young R, Pailler E, Billiot F, Drusch F, Barthelemy A, et al. (2012) Circulating tumor cells in lung cancer. Acta Cytol 56 :655-660.

70. Su DW, Nieva J (2017) Biophysical technologies for understanding circulating tumor cell biology and metastasis. Trans Lung Cancer Res $6: 473-485$.

71. Chikaishi Y, Yoneda K, Ohnaga T, Tanaka F (2017) EpCAM-independent capture of circulating tumor cells with a "universal CTC-chip". Oncol Rep $37: 77-82$. 